\title{
A social work study on the effect of family life education on marital satisfaction of women attending in Isfahan Counseling Centers
}

\author{
Aliasghar Rahimi Rezaee ${ }^{\mathrm{a}^{*}}$, Karim Afshari Neia ${ }^{\mathrm{b}}$ and Mokhtar Ariri ${ }^{\mathrm{c}}$
}

${ }^{a}$ Masters in Counselling Science, Isfahan, Iran

${ }^{b}$ Assistant Professor, Department of Psychology and Counselling, Islamic Azad University, Kermanshah, Iran

${ }^{c}$ Assistant professor Department counselling, Science and Research branch, Islamic Azad University, Kermanshah, Iran

\section{H R O N I C L E}

Article history:

Received January 20, 2013

Received in revised format

2 May 2013

Accepted 20 May 2013

Available online

May 262013

Keywords:

Family life education

Marital satisfaction

Women \begin{abstract}
A B S T R A C T
This paper studies the effective of family life education (FLE) on marital status among women attending in Isfahan counseling centers. The methodology of this research was quasi experimental with pre-test and post-test design and control group. Statistical populations were women attending in Isfahan city counseling centers. For selecting statistical sample, 30 women from women attending in counseling centers were selected as volunteers and randomly distributed between experimental and control groups. The main hypothesis of this research states that FLE increases marital satisfaction and their subscales in women. In this study, the dependent variable was marital-satisfaction and the independent variable was family life education conducted to case group in 10 sessions. The results of this survey show that the FLE improved marital satisfaction $(\mathrm{p}<0.01)$ and it was effective on the subscales $(\mathrm{p}<0.01)$.
\end{abstract}

\section{Introduction}

During the past few decades, we have seen tremendous change on human being's quality of life and life satisfaction and there are many studies associated with life satisfaction (Peebles, \& File, 1979; Brookman, 1984). Shore et al. (2008) investigated the effects of the Seizures and Epilepsy Education (SEE) program on improving quality of life, management of the seizure condition, and health care utilization among families having a child with epilepsy. They concluded that attending the SEE program could be beneficial to families having a child with epilepsy. Löfvenmark et al. (2011) investigated whether family members of patients with chronic heart failure (CHF) increased knowledge about CHF through a group-based multi-professional educational program and whether there was any impact on patients' health care utilization. They recommended that CHF education programs for family members could be provided at clinics, with information preferably repeated 2-3 times during a period of six months to maintain knowledge level. 
Aminjafari et al. (2012) performed an empirical study based on the implementation of factor analysis to detect various factors influencing people to have more stress in a hydropower unit located in city of Esfahan, Iran. They reported that among various factors, difficulty of working condition as well as work pressure were two most important factors increasing stress among employees. Iravani et al. (2013) performed an empirical study to find the relationship of three issues of age, gender and employment status on internet addiction behavior. They reported that internet addiction was more among singles than married (Chi-Square=19.94) and internet addition was more on men than women did, (Chi-Square=6.64). However, the survey did not find any evidence to believe job employment has any impact on internet addiction.

Jannesari et al. (2013) presented a study among 180 school principals in city of Khomeinishahr, located in province of Esfahan, Iran and examined ten hypotheses including the effects of personality trait neuroticism, extroversion, resilience, participative, conscientiousness on leadership style. The study examined the effects of two groups of leadership, namely transactional leadership and Laissezfair leadership styles on five personality traits. They reported that there were some meaningful relationship between transactional leadership and personality trait extraversion, resilience, participative and consciousness but there was not meaningful relationship between transactional leadership and personality trait neuroticism. In addition, while there were meaningful and positive relationship between Laissez-fair leadership style and personality trait extraversion as well as being resilience, the survey did not find any meaningful relationship between Laissez-fair leadership style and personality trait neuroticism, extraversion and being consciousness.

This paper studies the effective of family life education (FLE) on marital status among women attending in Isfahan counseling centers. The methodology of this research was quasi experimental with pre-test and post-test design and control group. The organization of this paper first presents details of our hypotheses in section 2 while section 3 presents the results and concluding remarks are given in the last to summarize the contribution of the paper.

\section{The proposed study}

The proposed study of this paper considers the following ten hypotheses,

1. FLE increases marital satisfaction in terms of distorting the ideal women.

2. FLE increases marital satisfaction among women.

3. FLE increases marital satisfaction in terms of women's personality.

4. FLE increases marital satisfaction in terms of women's life satisfaction.

5. FLE increases marital satisfaction in terms of resolving women's conflicts.

6. FLE increases marital satisfaction in terms of better financial management among women.

7. FLE increases marital satisfaction in terms of having more leisure among women.

8. FLE increases marital satisfaction in terms of distorting the ideal women.

9. FLE increases marital satisfaction in terms of having ideal parenting mothers.

10. FLE increases marital satisfaction in terms of having more friendly relationship with family and friends.

This paper studies the effective of family life education (FLE) on marital status among women attending in Isfahan counseling centers. The methodology of this research was quasi experimental with pre-test and post-test design and control group. Statistical populations were women attending in Isfahan city counseling centers. For selecting statistical sample, 30 women from women attending in counseling centers who were volunteer were selected and randomly distributed between experimental and control groups. Cronbach alpha has been calculated as 0.79 , which validates the overall survey. 


\section{The results}

In this section, we present details of our survey on testing the effect of FLE on women who were attending Isfahan counseling centers. Table 1 demonstrates the mean of experiment before/after the study was conducted.

Table 1

The summary of the test before/after accomplishment of experiment

\begin{tabular}{llcccc}
\hline Group & Experiment type & Mean & Standard deviation & F-value & P-value \\
\hline \multirow{2}{*}{ Experiment } & Pre-test & 183.66 & 31.0 & 1.74 & 0.198 \\
& Post-test & 211.40 & 26.78 & & \\
\hline \multirow{2}{*}{ Control } & Pre-test & 133.86 & 32.59 & 28.79 & 0.001 \\
& Post-test & 129.46 & 30.13 & & \\
\hline
\end{tabular}

The results of Table 1 indicate that mean of experiment was increased in the first group from 183 to 211. In order to find out more about the effects of each component we briefly discuss the issues. Table 2 summarizes the effect of FLE in terms of distorting the ideal women where we do not see any significant change in terms of distorting the ideal women.

Table 2

The results of testing FLE in terms of distorting the ideal women

\begin{tabular}{lllccc}
\hline Group & Experiment type & Mean & Standard deviation & F-value & P-value \\
\hline \multirow{2}{*}{ Experiment } & Pre-test & 17.36 & 3.77 & 1055.89 & 0.001 \\
& Post-test & 27.93 & 6.97 & & \\
\hline \multirow{2}{*}{ Control } & Pre-test & 13.26 & 4.89 & 29.90 & 0.001 \\
& Post-test & 22.33 & 8.65 & & \\
\hline
\end{tabular}

Similarly, we may look at the results of our survey in terms of marital satisfaction.

Table 3

The results of testing FLE in terms of marital satisfaction

\begin{tabular}{lllccc}
\hline Group & Experiment type & Mean & Standard deviation & F-value & P-value \\
\hline \multirow{2}{*}{ Experiment } & Pre-test & 29.20 & 5.64 & 2102.83 & 0.001 \\
& Post-test & 27.92 & 6.97 & & \\
\hline \multirow{2}{*}{ Control } & Pre-test & 20.40 & 5.64 & 59.99 & 0.001 \\
& Post-test & 22.33 & 8.65 & & \\
\hline
\end{tabular}

The result of Table 3 indicates an increase on mean of experiment group in terms of marital satisfaction. Table 4 shows the results of our survey in terms of women's personal characteristics.

Table 4

The results of testing FLE in terms of women's personal characteristics

\begin{tabular}{lllccc}
\hline Group & Experiment type & Mean & Standard deviation & F-value & P-value \\
\hline \multirow{2}{*}{ Experiment } & Pre-test & 14.06 & 4.55 & 1436.00 & 0.001 \\
& Post-test & 17.36 & 3.77 & & \\
\hline \multirow{2}{*}{ Control } & Pre-test & 11.33 & 4.16 & 15.84 & 0.001 \\
& Post-test & 13.26 & 4.89 & & \\
\hline
\end{tabular}

The results of Table 4 indicate some small increase on mean score of women's personal characteristics after the test has been accomplished. Table 5 demonstrates the results of our survey in terms of capability of building a good communication where the results of women's capabilities have 
been slightly improved. Table 6 presents the results of the effect of FLE on increasing women's capabilities to resolve their family conflicts.

Table 5

The results of testing FLE in terms of women's capabilities to build good communication

\begin{tabular}{llcccc}
\hline Group & Experiment type & Mean & Standard deviation & F-value & P-value \\
\hline \multirow{2}{*}{ Experiment } & Pre-test & 14.33 & 4.62 & 1453.57 & 0.001 \\
& Post-test & 16.38 & 3.95 & & \\
\hline Control & Pre-test & 9.93 & 2.78 & 30.54 & 0.001 \\
& Post-test & 13.73 & 5.10 & & \\
\hline
\end{tabular}

Table 6

The results of testing FLE in terms of women's capabilities to resolve conflicts

\begin{tabular}{lllccc}
\hline Group & Experiment type & Mean & Standard deviation & F-value & P-value \\
\hline Experiment & Pre-test & 18.46 & 4.10 & 1678.02 & 0.001 \\
& Post-test & 18.94 & 5.01 & & \\
\hline Control & Pre-test & 12.00 & 3.74 & 42.61 & 0.001 \\
& Post-test & 15.80 & 6.54 & & \\
\hline
\end{tabular}

The results of Table 6 demonstrate the effect of FLE on helping women better handle family conflicts and the results do not show any change on women's capabilities. Table 7 demonstrates the results of our survey in terms of their capability on improving their skills for financial management.

Table 7

The results of testing FLE in terms of women's capabilities for financial management

\begin{tabular}{lllccc}
\hline Group & Experiment type & Mean & Standard deviation & F-value & P-value \\
\hline \multirow{2}{*}{ Experiment } & Pre-test & 13.86 & 3.02 & 557.14 & 0.001 \\
& Post-test & 14.70 & 3.39 & & \\
\hline \multirow{2}{*}{ Control } & Pre-test & 10.33 & 4.30 & 15.83 & 0.001 \\
& Post-test & 12.53 & 3.39 & & \\
\hline
\end{tabular}

The results of Table 7 show that women could slightly improve their skills for better managing family in terms of financial affairs. Next, we present details of our survey in terms of leisure and entertainment affairs. Unfortunately,

Table 8

The results of testing FLE in terms of leisure and entertainment

\begin{tabular}{lllccc}
\hline Group & Experiment type & Mean & Standard deviation & F-value & P-value \\
\hline \multirow{2}{*}{ Experiment } & Pre-test & 18.13 & 3.99 & 890.13 & 0.001 \\
& Post-test & 16.66 & 3.14 & & \\
\hline \multirow{2}{*}{ Control } & Pre-test & 13.06 & 3.50 & 12.05 & 0.001 \\
& Post-test & 15.16 & 4.78 & & \\
\hline
\end{tabular}

Next, we present details of our survey in terms of marital satisfaction and Table 9 demonstrates the results of our survey where there is basically not much change on this figure after experiment. The results of Table 10 and Table 11 do not show any significant changes on the mean scores for having ideal parenting mothers as well as having better relationship with friends and families and improving sense of spirituality among women. 
Table 9

The results of testing FLE in terms of marital satisfaction

\begin{tabular}{lllccc}
\hline Group & Experiment type & Mean & Standard deviation & F-value & P-value \\
\hline \multirow{2}{*}{ Experiment } & Pre-test & 17.33 & 3.24 & 2489.84 & 0.001 \\
& Post-test & 17.53 & 4.95 & & \\
\hline \multirow{2}{*}{ Control } & Pre-test & 13.86 & 4.12 & 22.25 & 0.001 \\
& Post-test & 14.43 & 5.11 & & \\
\hline
\end{tabular}

Table 10

The results of testing FLE in terms of in terms of having ideal parenting mothers

\begin{tabular}{lllccc}
\hline Group & Experiment type & Mean & Standard deviation & F-value & P-value \\
\hline \multirow{2}{*}{ Experiment } & Pre-test & 17.80 & 4.58 & 2386.53 & 0.001 \\
& Post-test & 17.11 & 4.00 & & \\
\hline \multirow{2}{*}{ Control } & Pre-test & 12.13 & 2.74 & 14.99 & 0.001 \\
& Post-test & 15.40 & 4.13 & & \\
\hline
\end{tabular}

Table 11

The results of testing FLE on friends and families

\begin{tabular}{lllccc}
\hline Group & Experiment type & Mean & Standard deviation & F-value & P-value \\
\hline \multirow{2}{*}{ Experiment } & Pre-test & 14.46 & 4.15 & 435.33 & 0.001 \\
& Post-test & 14.56 & 2.44 & & \\
\hline Control & Pre-test & 11.86 & 3.31 & 12.09 & 0.002 \\
& Post-test & 12.10 & 3.34 & & \\
\hline
\end{tabular}

Table 12

The results of testing FLE on improving sense of spirituality among women

\begin{tabular}{lllccc}
\hline Group & Experiment type & Mean & Standard deviation & F-value & P-value \\
\hline \multirow{2}{*}{ Experiment } & Pre-test & 15.00 & 3.02 & 2.7 & 0.111 \\
& Post-test & 16.06 & 3.63 & & \\
\hline \multirow{2}{*}{ Control } & Pre-test & 11.26 & 3.80 & 9.79 & 0.004 \\
& Post-test & 9.80 & 4.17 & & \\
\hline
\end{tabular}

\section{Discussion and Conclusion}

This paper studied the effective of family life education (FLE) on marital status among women attending in Isfahan counseling centers. The study selected a group of people who came to counseling services and divided them into two groups of control and experiment. The study examined whether FLE could increase marital satisfaction and their subscales in women. In this study, the dependent variable was marital-satisfaction and the independent variable was family life education conducted to case group in 10 sessions. The results of this survey have confirmed that the FLE improved marital satisfaction $(\mathrm{p}<0.01)$ and it was effective on the subscales $(\mathrm{p}<0.01)$.

\section{References}

Aminjafari, B., Ghojavand, K., Iravani, G., Iravani, M \& Vakili, D. (2012). A social work study using factor analysis on detecting important factors creating stress: A case study of hydro-power employees. Management Science Letters, 2(5), 1761-1768.

Brookman, R.R. (1984). Planned parenthood Federation of America, Inc. Latino Families in the United States. A Resourcebook for Family Life Education. Journal of Adolescent Health Care, 5(3), 219. 
Iravani, M., Rajabi, M., Abbasi, M \& Jannesari, H. (2013). A social work study on impact of gender, marital status and employment status on internet addiction. Management Science Letters, 3(3), 1019-1024.

Jannesari, H., Iravani, M., Masaeli, A., Dareshori, E \& Ghorbani, A. (2013). A social work study on relationship between transactional and laissez-fair leadership style and personality traits: A case study of educational system. Management Science Letters, 3(3), 813-820.

Löfvenmark, C., Karlsson, M.R., Edner, M., Billing, E., \& Mattiasson, A.C. (2011). A group-based multi-professional education programme for family members of patients with chronic heart failure: Effects on knowledge and patients' health care utilization. Patient Education and Counseling, 85(2), e162-e168.

Peebles, W.C., File, P.J. (1979). Family life education for day care programs serving the black community. Children and Youth Services Review, 1(4), 405-422.

Shore, C.P., Perkins, S.M., \& Austin, J.K. (2008). The Seizures and Epilepsy Education (SEE) Program for families of children with epilepsy: A preliminary study. Epilepsy \& Behavior, 12(1), 157-164. 